Gary R. MacVicar • Maha Hussain

\title{
Chemotherapy for prostate cancer: implementing early systemic therapy to improve outcomes
}

Published online: 5 November 2005

(c) Springer-Verlag 2005

\begin{abstract}
Prostate cancer remains a significant health concern for men in the USA as it is a leading cancer diagnosis and a cause of death. With the use of prostatespecific antigen for screening, a stage migration has occurred with an increase in the number of men diagnosed with early-stage disease. The optimal primary management of these men is evolving, but despite adequate local treatment a significant percentage will develop either biochemical or clinical evidence of recurrent disease. Several criteria for risk stratification have been developed, thus, improving the ability to identify a high-risk population. Small studies have been reported demonstrating the feasibility of neoadjuvant or adjuvant chemotherapy in conjunction with either radiation or radical prostatectomy in this high-risk population, and large phase III studies are ongoing. With the advent of life-prolonging chemotherapy in the hormone-refractory setting, attention must now also be given to early-stage disease so as to develop multi-modality approaches with the hope of increasing survival and ultimately providing a cure.
\end{abstract}

Keywords Prostate cancer - Adjuvant therapy $\cdot$ Neoadjuvant therapy $\cdot$ Multimodality therapy $\cdot$ Chemotherapy

This work was presented at the 20th Bristol-Myers Squibb Nagoya International Cancer Treatment Symposium, "New Concepts of Treatment Strategies for Hormone-Related Cancer", 11-12 March 2005, Nagoya, Japan.

M. Hussain $(\bowtie)$

University of Michigan Comprehensive Cancer Center,

7314 CCGC, 1500 E. Medical Center Drive,

Ann Arbor, MI 48109-0946, USA

E-mail: mahahuss@umich.edu

Tel.: + 1-734-9368906

Fax: + 1-734-6152719

G. R. MacVicar

Division of Hematology/Oncology, Northwestern University, Chicago, IL 60611, USA

\section{Introduction}

In 2005, an estimated 230,090 men will be diagnosed with prostate cancer and 30,350 will die secondary to their disease [24]. Radical prostatectomy and radiation therapy can be curative for many men with early-stage disease, but a portion will experience relapse following local therapy. Medical or surgical castration remains the initial treatment of choice for men who present with or develop metastatic disease. While the majority of these patients will initially respond to androgen deprivation, the duration of their response is only in the order of 18 24 months [10, 16]. After progressing to androgen independence, median survival is approximately 16 18 months $[36,48,51]$ and the majority of these patients die of metastatic prostate cancer.

Historically, chemotherapy has not been viewed as having a crucial role in the management of patients with prostate cancer. The failure of a variety of regimens to show significant responses and survival benefits in the hormone-refractory population led many researchers to believe that chemotherapy should not be considered standard for advanced prostate cancer patients, with the exception of participation in clinical trials for select patients [49]. This opinion began to change with the inclusion of quality-of-life endpoints in clinical trials evaluating the utility of chemotherapy for men with androgen-independent prostate cancer. Two randomized phase III trials have shown improved pain control with mitoxantrone and either prednisone or hydrocortisone over steroids alone in this patient population, but these studies did not demonstrate significant impacts on overall survival $[26,50]$.

Building on these findings, efforts have focused on utilizing newer agents. Of the cytotoxic therapies, taxanes have been extensively investigated with particular attention given to docetaxel, which targets the cellular microtubules. The drug binds to tubulin, stabilizes microtubule formation and inhibits depolymerization. Phase II trials have demonstrated prostate-specific 
antigen (PSA) declines of $>50 \%$ in $38-46 \%$ of hormone-refractory patients treated with $75 \mathrm{mg} / \mathrm{m}^{2}$ of docetaxel every 3 weeks, and measurable disease responses occurred in $28-60 \%$ of patients $[17,38]$. Weekly schedules have also been investigated and reports suggest that they have significant levels of activity [2, 4]. Hematologic toxicity was a concern in all of these trials, and grade 3 or 4 neutropenia occurred in $43 \%$ of patients who received docetaxel once every 3 weeks. Although the frequency of neutropenia was less with weekly regimens, neutropenic fever and hospitalization were rare events with either dosing schedule.

These encouraging phase II data led to two phase III randomized trials comparing docetaxel versus mitoxantrone regimens in men with androgen-independent prostate cancer. The Southwest Oncology Group (SWOG) demonstrated in SWOG 9916 a significantly improved median survival of 18 months with the combination of docetaxel and estramustine administered every 3 weeks as compared to 15 months with mitoxantrone and prednisone. Time to progression was also superior for docetaxel plus estramustine: 6 months versus 3 months for mitoxantrone and prednisone [36]. The second study, TAX 327, also showed superiority of docetaxel over mitoxantrone. Docetaxel, when given $75 \mathrm{mg} / \mathrm{m}^{2}$ every 3 weeks with a daily dosage of prednisone, provided median survival of 18.9 months. These results were statistically significant compared with the 16.5-month median survival in patients who received mitoxantrone and prednisone. A third arm utilized $30 \mathrm{mg} / \mathrm{m}^{2}$ of docetaxel which was given weekly for 5 weeks of 6-week cycles, and the median survival of 17.4 months was not statistically significant compared with the mitoxantrone arm [51]. From a quality-of-life standpoint, the 3-week docetaxel regimen resulted in significantly improved pain control over mitoxantrone. These studies are important in that they are the first to report a survival advantage as well as palliative benefits with chemotherapy in hormone-refractory prostate cancer, thus establishing docetaxel as the standard therapy in this setting, and laying the foundation for investigating chemotherapy in earlier stages of prostate cancer.

\section{Clinically localized prostate cancer}

With the development of PSA-based early detection strategies for prostate cancer, a stage migration has occurred with a resultant increase in the number of men with clinically localized prostate cancer [21]. Fiveyear survival rates in men with prostate cancer have significantly improved over the last few decades, perhaps due to earlier detection and improvements of local control [23]. However, local therapy does not cure all patients with localized disease, as shown in a pooled analysis of men who received radiation where $34 \%$ exhibited biochemical recurrence at 5 years [47]. In large reported series of men who underwent radical prostatectomy, $15-31 \%$ went on to exhibit biochemical evidence of recurrent disease [25, 40, 41]. Specifically, Pound et al. [40] reported that $34 \%$ of men with a rising PSA after radical prostatectomy were found to have metastatic disease at a median of 8 years; moreover, once metastases were detected they had a median time to death of 5 years. Therefore, while a large portion of men are essentially cured of their prostate cancer by local therapy, a segment of patients with clinically localized disease are at high risk for future relapse and possibly death from their disease.

Experience with other solid tumors including breast, lung and colon cancer suggests that even modestly active systemic chemotherapy can have curative potential when administered in the adjuvant setting. In prostate cancer, efforts have begun to evaluate the role of systemic therapy in patients with high-risk localized or locally advanced disease. For obvious reasons, the most studied treatment option has been androgen ablation. Several trials have been performed to evaluate the role of neoadjuvant and adjuvant hormonal therapy in combination with radical prostatectomy or radiation therapy. Neoadjuvant hormonal therapy prior to radical prostatectomy for patients with localized or locally advanced prostate cancer has resulted in decreased positive margin rates but with no survival benefit $[8,46,52]$. Alternatively, men who are found to have lymph node metastases at radical prostatectomy have been shown to have a survival benefit and a decreased risk of recurrence with immediate as opposed to delayed adjuvant hormonal therapy [32].

Trials evaluating radiation therapy in conjunction with androgen deprivation have shown benefits with the addition of hormonal therapy. In a European Organization for Research and Treatment of Cancer (EORTC) study, men with locally advanced prostate cancer had improved overall and disease-free survival with radiation combined with 3 years of androgen deprivation versus radiation alone [6]. In this study, 5-year diseasefree survival was $62 \%$ in the combination arm, and distant metastases accounted for the majority of recurrences suggesting that androgen deprivation is not sufficient systemic therapy to prevent metastatic disease.

Prostate cancer is thought to be heterogeneous in composition, with both androgen-dependent and androgen-independent clones, and hormonal manipulations may select for insensitive cells that remain viable and capable of uncontrolled growth. This concept is supported by the observed suboptimal outcome with adjuvant hormones and would argue for the need to investigate early chemotherapy. While more progress is needed, data from recent phase III trials demonstrate for the first time that prostate cancer is not a chemoresistant disease, thus opening the door to a new era of investigations in the setting of early-stage disease. Critical to the success of this effort is the ability to identify highrisk patient populations whose benefit from treatment will likely outweigh chemotherapy-related toxicities and complications. 


\section{Identifying high-risk disease}

Until recently, stage and Gleason score have been the backbone for risk prediction. PSA has also been incorporated into risk assessment, and several models and nomograms have been developed that stratify patients for risk of recurrence. Partin et al. [34] were the first to combine these three characteristics so as to predict preoperatively the final pathologic stage and likelihood of organ-confined prostate cancer. Serum PSA, pretreatment biopsy Gleason score, and clinical stage each independently predicted pathologic stage, but results were improved by combining all three factors. This model has been validated in retrospective analyses of men treated with either radical prostatectomy or radiation therapy $[5,31]$, and an updated version of the tables has been published [35].

D'Amico et al. have utilized clinical characteristics to risk-stratify patients by likelihood of biochemical recurrence at 5 years [12] and 10 years [11] following local therapy. Results suggest that patients can be stratified by pretreatment PSA, biopsy Gleason score and 1992 AJCC $\mathrm{T}$ stage in terms of risk of biochemical recurrence at 5 years. Low-risk patients (stage T1c or T2a, and PSA $\leq 10 \mathrm{ng} / \mathrm{ml}$, and Gleason score $\leq 6$ ) have an estimated 5-year biochemical failure-free rate of $>80 \%$. Intermediate-risk patients (stage T2b, PSA 11-20 ng/ml, Gleason score 7) have failure-free rates of about $60 \%$, and high-risk patients (stage $>$ T2c or PSA $>20 \mathrm{ng} / \mathrm{ml}$ or Gleason score $>7$ ) have an estimated rate of $<40 \%$.

Kattan et al., using similar clinical characteristics, have developed a continuous probability nomogram to predict likelihood of biochemical recurrence following primary therapy for localized prostate cancer. While risk-stratification models are easy for clinicians to remember and apply to patients, these probability nomograms place patients on a continuous spectrum of risk recurrence rather than in heterogeneous risk groups, potentially resulting in a more accurate assessment. Pretreatment nomograms for radiation therapy [29] and radical prostatectomy [27] as well as a postprostatectomy nomogram [28] have been developed to predict freedom from recurrence. Both the pre- and postoperative nomograms have been validated [18, 19]; furthermore, the preoperative nomogram was validated using a large international dataset suggesting that the model is accurate even in the setting of a heterogeneous patient population [19].

Prostate-specific antigen kinetics, which have been shown to be predictive of prostate cancer-specific mortality in the hormone refractory setting [13], may also be useful in identifying men with clinically localized disease who are likely to die of their disease. A recent study suggests that men with $\mathrm{T} 1 \mathrm{c}$ or $\mathrm{T} 2$ disease who have a PSA velocity $>2.0 \mathrm{ng} / \mathrm{ml}$ in the year prior to treatment, are at significantly increased risk of biochemical disease recurrence, death from prostate cancer, and death from any cause [14].
These tools are useful to clinicians when counseling their patients and for risk stratification in clinical trials. However, consideration must be given to the fact that they have not been tested prospectively.

\section{Adjuvant chemotherapy}

By comparison with other solid tumors, multimodality approaches to early-stage prostate cancer are still in their infancy. Several trials dating back to the 1970s and 1980s have attempted to address this issue. With an adjuvant approach, patient selection is improved since treatment decisions are based on accurate pathologic surgical staging, and the number of patients who unnecessarily receive cytotoxic chemotherapy is reduced.

Between 1978 and 1985, the National Prostate Cancer Project (NPCP) initiated two protocols which were designed to test the efficacy and toxicity of adjuvant chemotherapy following radical prostatectomy (Protocol 900) or definitive radiation (Protocol 1000) [43-45]. Men at high risk of recurrence were randomized to receive 2 years of either cyclophosphamide or estramustine versus observation alone following primary therapy. Patients who received cyclophosphamide did not have improved progression-free survival relative to the observation arm in either the prostatectomy or radiation protocol. However, node-positive patients treated with radiation and estramustine had a $60 \%$ recurrence rate versus $81 \%$ in the observation arm $(P<0.05)$. In particular, stage $\mathrm{C}$ patients who underwent prostatectomy and patients with grade 3 tumors, regardless of local therapy, benefited from estramustine. While this is the largest study published on the investigation of the use of adjuvant chemotherapy in high-risk disease, the trial was underpowered to reliably answer the question regarding efficacy of systemic therapy in this population.

The remaining published trials of adjuvant chemotherapy in patients with high-risk disease suffer from small sample sizes and methodological limitations (Table 1). One of the most recent trials suggesting benefits of early chemotherapy is a study by Wang et al. [53] who evaluated adjuvant mitoxantrone in men with advanced prostate cancer, a number of whom had locally advanced disease. Patients were randomized to receive either hormonal therapy alone consisting of luteinizing hormone-releasing hormone agonist and flutamide or hormonal therapy with mitoxantrone. No advantage to mitoxantrone was identified in the metastatic population. However, patients with localized disease, who received hormonal therapy and mitoxantrone, had improved median survival over patients on hormonal therapy alone [53].

Collectively, however, these studies are too small to draw firm conclusions regarding the effects of adjuvant chemotherapy on survival in men with high-risk prostate cancer, but they suggest that multimodal therapy is feasible in this population. Only through carefully designed 


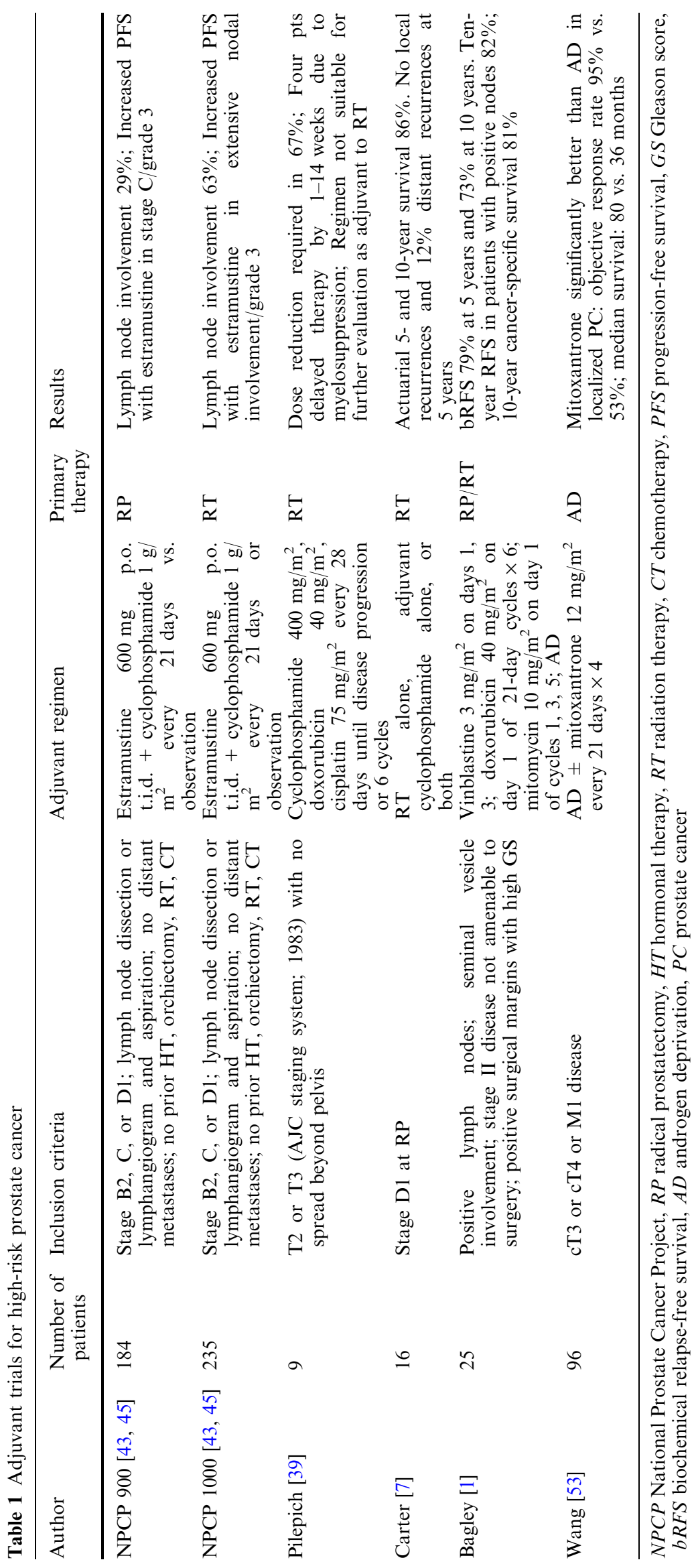


and conducted prospective, randomized, controlled trials will questions regarding the utility of adjuvant chemotherapy be adequately answered.

\section{Neoadjuvant chemotherapy}

Neoadjuvant chemotherapy has also been actively investigated (Table 2), and this approach has several benefits. Micrometastatic disease, which is present at the time of diagnosis and is a source of potential failure for local treatment, is treated without delay. Locally advanced tumors, if responsive to chemotherapy, are reduced in size such that they are more amenable to local therapy. Postoperative pathologic specimens may be collected and analyzed to confirm efficacy of treatment. Such an approach may also provide a model for efficient drug development, with opportunities to evaluate targeted therapies as well as improve understanding of mechanisms of response and resistance to treatment utilizing human specimens. Several groups have published results of trials evaluating neoadjuvant chemotherapy with or without androgen ablation for clinically localized prostate cancer. However, these studies are difficult to compare due to the small numbers of patients included, the differences in eligibility criteria, and the variety of chemotherapeutic agents and regimens utilized.

Many of the high-risk prostate cancer neoadjuvant trials have included estramustine combined with other chemotherapeutic agents $[9,30,37]$. Thromboembolic events related to estramustine were reported in each of these studies. Positive surgical margin rates have been favorable, and clinical downstaging of patients after neoadjuvant treatment prior to prostatectomy has been reported $[9,30]$. However, residual disease was identified in post-prostatectomy specimens of all patients included in these trials.

Two groups have reported results of neoadjuvant estramustine-based chemotherapy prior to radiotherapy. Zelefsky et al. [54] treated men with unfavorable risk profiles with two cycles of neoadjuvant estramustine/ vinblastine followed by a third cycle given concurrently with radiation, while Ben-Josef et al. [3] reported results of two cycles of neoadjuvant estramustine and etoposide followed by concurrent estramustine and three-dimensional conformal radiotherapy. Chemotherapy and radiation-related toxicity profiles were reasonable; however, thromboembolic complications attributable to estramustine were reported by both investigators.

Two groups have reported results of single-agent docetaxel given either for 6 months [33] or 6 weeks [15] prior to prostatectomy. In the study by Dreicer et al. [15], residual disease was identified in all prostatectomy specimens and $89 \%$ of the specimens had extracapsular extension. Hussain et al. [22] treated patients with highrisk disease with neoadjuvant docetaxel and estramustine prior to either radiation or radical prostatectomy. Among patients who underwent radical prostatectomy,
$70 \%$ had negative surgical margins but none achieved pathologic complete remission. Preradiotherapy prostate biopsies were negative in 2 of 11 patients.

These studies are all too small to draw conclusions regarding the efficacy of neoadjuvant chemotherapy. However, like the adjuvant studies they do demonstrate feasibility and acceptability among patients who were administered chemotherapy in the early-disease setting. Aside from some serious thromboembolic complications likely due to estramustine, chemotherapy was overall well tolerated. Surgery following chemotherapy largely did not result in an increased rate of significant surgical complications. Clark et al. [9] noted a desmoplatic reaction around the prostate, potentially making surgery more difficult. They were nonetheless successfully able to perform radical prostatectomies on all patients included in their study. One should note that PSA response does not appear to be as significant in the early stages of disease as believed in hormone-refractory populations. Although several of the neoadjuvant studies noted significant PSA responses prior to primary treatment, residual tumor was identified in all postsurgical specimens. It is unclear why no pathological complete responses were observed. Similarly it is not clear how to assess response/efficacy in phase II trials of neoadjuvant chemotherapy and what the most appropriate endpoints are. In other neoplasms such as bladder cancer, a complete pathologic response is possible following neoadjuvant chemotherapy and has been shown to be a useful prognostic factor [20].

\section{Phase III trials of adjuvant and neoadjuvant chemotherapy}

Cooperative groups have led the way by initiating phase III trials to address the role of systemic therapy in earlystage high-risk prostate cancer. Several ongoing and planned protocols are listed in Table 3. These are large trials that are adequately powered to detect meaningful differences in survival with the addition of systemic chemotherapy.

The first is an important trial led by the Southwest Oncology Group (S9921). Eligible men must have Gleason scores $8-10$, pathologic stage $\geq \mathrm{pT} 3 \mathrm{~b}$, or nodal involvement or Gleason score 7 and positive margins. Following radical prostatectomy, patients are randomized to combined androgen blockade for 2 years or mitoxantrone and prednisone for six cycles and combined androgen blockade for 2 years. Patients with positive surgical margins are permitted to receive adjuvant radiation. A total of 1,360 enrolled subjects are needed to achieve $92 \%$ power to detect a $30 \%$ increase of median survival in the chemotherapy arm by a one-sided $t$ test and a significance level of 0.05 .

A phase III randomized trial investigating the role of neoadjuvant chemotherapy is planned by Cancer and Leukemia Group B (CALGB 90203). Eligible patients must have $<60 \%$ chance of being disease-free 5 years 


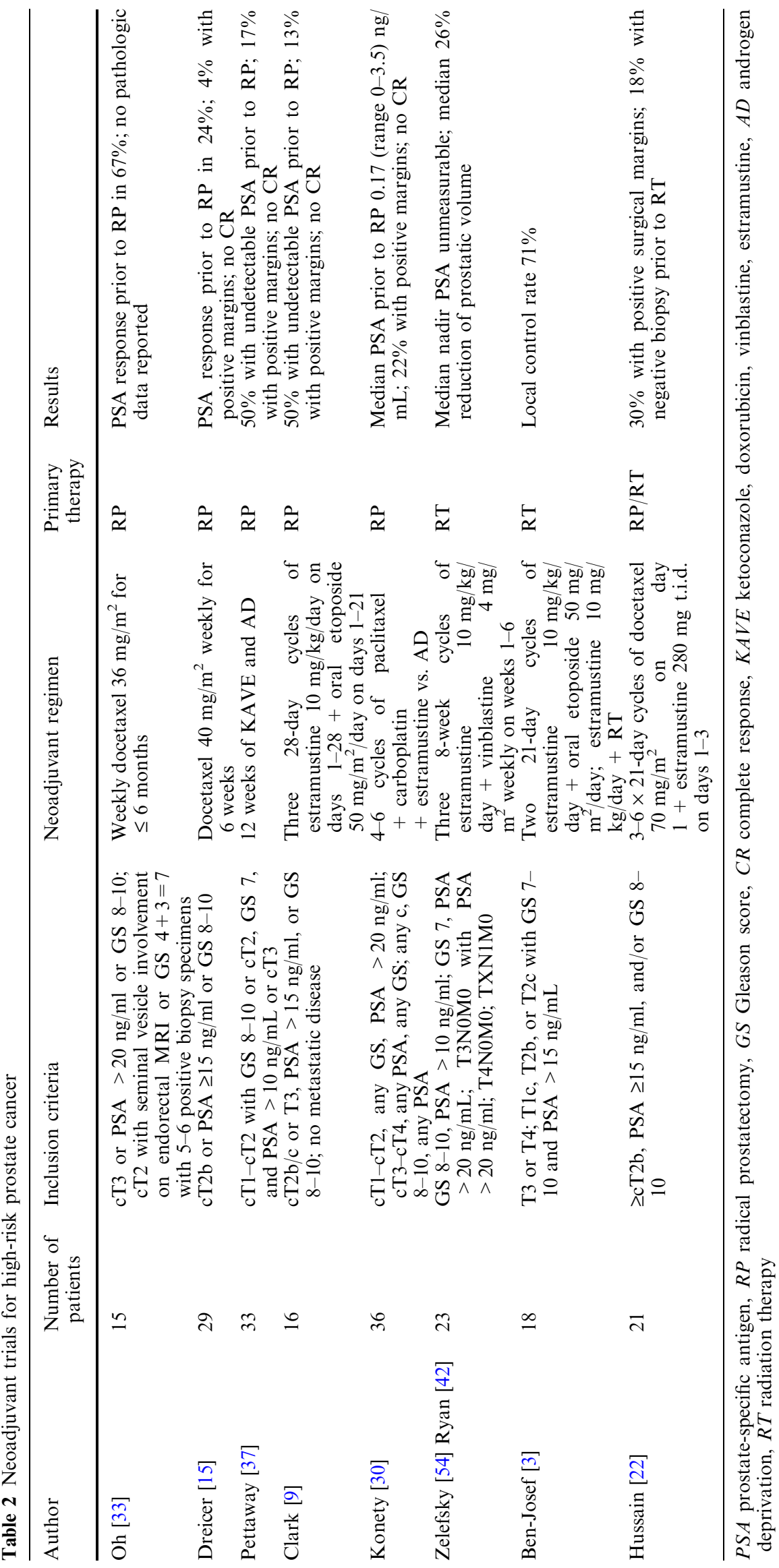


Table 3 Phase III neoadjuvant and adjuvant trials in high-risk localized prostate cancer

\begin{tabular}{|c|c|c|c|c|c|c|}
\hline Trial & $\begin{array}{l}\text { Treatment } \\
\text { approach }\end{array}$ & Eligibility criteria & $\begin{array}{l}\text { Local } \\
\text { therapy }\end{array}$ & Randomization & $\begin{array}{l}\text { Number of } \\
\text { patients }\end{array}$ & $\begin{array}{l}\text { Primary } \\
\text { endpoint }\end{array}$ \\
\hline CALGB 90203 & Neoadjuvant & $\begin{array}{l}\leq 60 \% \text { PFS at } 5 \text { years estimated } \\
\text { by preoperative nomogram }\end{array}$ & $\mathrm{RP}$ & $\begin{array}{l}\text { Docetaxel }+ \text { prednisone }+ \text { AD vs. } \\
\text { surgery }\end{array}$ & 750 & PFS \\
\hline SWOG 9921 & Adjuvant & $\begin{array}{l}\text { GS } 8-10, \geq \mathrm{pT} 3, \text { or positive } \\
\text { nodes; GS } 7 \text { and positive margin }\end{array}$ & $\mathrm{RP}$ & $\begin{array}{l}\text { AD } \times 2 \text { years vs. mitoxantrone }+ \\
\text { prednisone followed by } \mathrm{AD} \text { for } 2 \text { years }\end{array}$ & 1,360 & OS \\
\hline Sanofi-Aventis & Adjuvant & pT3, node positive, or GS 8-10 & $\mathrm{RP}$ & $\begin{array}{l}\text { Early vs. delayed treatment consisting } \\
\text { of } A D \text { alone or } A D \text { and docetaxel }\end{array}$ & 2,172 & PFS \\
\hline
\end{tabular}

$C A L G B$ Cancer and Leukemia Group B, SWOG Southwest Oncology Group, PFS progression-free survival, $R P$ radical prostatectomy, $A D$ androgen deprivation, $G S$ Gleason score, $O S$ overall survival

following prostatectomy based on the Kattan nomogram and a life expectancy of $\geq 10$ years. Patients will be randomized to radical prostatectomy alone or neoadjuvant estramustine and docetaxel followed by radical prostatectomy. Planned accrual is 750 men with a $90 \%$ power to detect a $36 \%$ decrease in 5-year recurrence rates, which is the primary endpoint of the study.

An industry-sponsored trial is also being planned to evaluate the role of early versus delayed treatment, consisting of androgen deprivation alone or with docetaxel, in a high-risk population following radical prostatectomy.

\section{Conclusions}

Improvements of systemic therapy for prostate cancer over the past decade have opened the door for active investigation of novel and effective treatments in all stages of the disease. One of the major results of this progress is the initiation of several large randomized clinical trials in early-stage disease. This approach has been enriched by improvements in risk prediction and the recognition that outcome improvement, much like in other cancers, is dependent on multimodal therapy. Such approaches are gaining increasing acceptability among patients and physicians. Defeating prostate cancer will require solid commitment to continued clinical/translational research in this area and to offer access to clinical trials to all appropriate patients.

\section{References}

1. Bagley CM Jr, Lane RF, Blasko JC, Grimm PD, Ragde H, Cobb OE, Rowbotham RK (2002) Adjuvant chemohormonal therapy of high risk prostate carcinoma. Ten year results. Cancer 94:2728-2732

2. Beer TM, Pierce WC, Lowe BA, Henner WD (2001) Phase II study of weekly docetaxel in symptomatic androgen-independent prostate cancer. Ann Oncol 12:1273-1279

3. Ben-Josef E, Porter AT, Han S, Mertens W, Chuba P, Fontana J, Hussain M (2001) Neoadjuvant estramustine and etoposide followed by concurrent estramustine and definitive radiotherapy for locally advanced prostate cancer: feasibility and preliminary results. Int $\mathbf{J}$ Radiat Oncol Biol Phys 49:699703
4. Berry W, Dakhil S, Gregurich MA, Asmar L (2001) Phase II trial of single-agent weekly docetaxel in hormone-refractory, symptomatic, metastatic carcinoma of the prostate. Semin Oncol 28:8-15

5. Blute ML, Bergstralh EJ, Partin AW, Walsh PC, Kattan MW, Scardino PT, Montie JE, Pearson JD, Slezak JM, Zincke H (2000) Validation of Partin tables for predicting pathological stage of clinically localized prostate cancer. J Urol 164:15911595

6. Bolla M, Gonzalez D, Warde P, Dubois JB, Mirimanoff RO, Storme G, Bernier J, Kuten A, Sternberg C, Gil T, Collette L, Pierart M (1997) Improved survival in patients with locally advanced prostate cancer treated with radiotherapy and goserelin. N Engl J Med 337:295-300

7. Carter GE, Lieskovsky G, Skinner DG, Petrovich Z (1989) Results of local and/or systemic adjuvant therapy in the management of pathological stage C or D1 prostate cancer following radical prostatectomy. J Urol 142:1266-1270

8. Cher ML, Shinohara K, Breslin S, Vapnek J, Carroll PR (1995) High failure rate associated with long-term follow-up of neoadjuvant androgen deprivation followed by radical prostatectomy for stage C prostatic cancer. Br J Urol 75:771-777

9. Clark PE, Peereboom DM, Dreicer R, Levin HS, Clark SB, Klein EA (2001) Phase II trial of neoadjuvant estramustine and etoposide plus radical prostatectomy for locally advanced prostate cancer. Urology 57:281-285

10. Crawford ED, Eisenberger MA, McLeod DG, Spaulding JT, Benson R, Dorr FA, Blumenstein BA, Davis MA, Goodman PJ (1989) A controlled trial of leuprolide with and without flutamide in prostatic carcinoma. N Engl J Med 321:419-424

11. D'Amico AV (2001) Combined-modality staging for localized adenocarcinoma of the prostate. Oncology 15:1049-1059

12. D'Amico AV, Whittington R, Malkowicz SB, Schultz D, Blank K, Broderick GA, Tomaszewski JE, Renshaw AA, Kaplan I, Beard CJ, Wein A (1998) Biochemical outcome after radical prostatectomy, external beam radiation therapy, or interstitial radiation therapy for clinically localized prostate cancer. JAMA 280:969-974

13. D'Amico AV, Moul JW, Carroll PR, Sun L, Lubeck D, Chen MH (2003) Surrogate end point for prostate cancer-specific mortality after radical prostatectomy or radiation therapy. $\mathbf{J}$ Natl Cancer Inst 95:1376-1383

14. D'Amico AV, Chen MH, Roehl KA, Catalona WJ (2004) Preoperative PSA velocity and the risk of death from prostate cancer after radical prostatectomy. $\mathrm{N}$ Engl $\mathrm{J}$ Med 351:125-135

15. Dreicer R, Magi-Galluzzi C, Zhou M, Rothaermel J, Reuther A, Ulchaker J, Zippe C, Fergany A, Klein EA (2004) Phase II trial of neoadjuvant docetaxel before radical prostatectomy for locally advanced prostate cancer. Urology 63:1138-1142

16. Eisenberger MA, Blumenstein BA, Crawford ED, Miller G, McLeod DG, Loehrer PJ, Wilding G, Sears K, Culkin DJ, Thompson IM Jr, Bueschen AJ, Lowe BA (1998) Bilateral orchiectomy with or without flutamide for metastatic prostate cancer. N Engl J Med 339:1036-1042 
17. Friedland D, Cohen J, Miller R Jr, Voloshin M, Gluckman R, Lembersky B, Zidar B, Keating M, Reilly N, Dimitt B (1999) A phase II trial of docetaxel (Taxotere) in hormone-refractory prostate cancer: correlation of antitumor effect to phosphorylation of Bcl-2. Semin Oncol 26:19-23

18. Graefen M, Karakiewicz PI, Cagiannos I, Klein E, Kupelian PA, Quinn DI, Henshall SM, Grygiel JJ, Sutherland RL, Stricker PD, de Kernion J, Cangiano T, Schroder FH, Wildhagen MF, Scardino PT, Kattan MW (2002) Validation study of the accuracy of a postoperative nomogram for recurrence after radical prostatectomy for localized prostate cancer. J Clin Oncol 20:951-956

19. Graefen M, Karakiewicz PI, Cagiannos I, Quinn DI, Henshall SM, Grygiel JJ, Sutherland RL, Stricker PD, Klein E, Kupelian P, Skinner DG, Lieskovsky G, Bochner B, Huland H, Hammerer PG, Haese A, Erbersdobler A, Eastham JA, de Kernion J, Cangiano T, Schroder FH, Wildhagen MF, van der Kwast TH, Scardino PT, Kattan MW (2002) International validation of a preoperative nomogram for prostate cancer recurrence after radical prostatectomy. J Clin Oncol 20:3206-3212

20. Grossman HB, Natale RB, Tangen CM, Speights VO, Vogelzang NJ, Trump DL, deVere White RW, Sarosdy MF, Wood DP Jr, Raghavan D, Crawford ED (2003) Neoadjuvant chemotherapy plus cystectomy compared with cystectomy alone for locally advanced bladder cancer. $\mathrm{N}$ Engl J Med 349:859-866

21. Han M, Partin AW, Piantadosi S, Epstein JI, Walsh PC (2001) Era specific biochemical recurrence-free survival following radical prostatectomy for clinically localized prostate cancer. J Urol 166:416-419

22. Hussain M, Smith DC, El-Rayes BF, Du W, Vaishampayan U, Fontana J, Sakr W, Wood D (2003) Neoadjuvant docetaxel and estramustine chemotherapy in high-risk/locally advanced prostate cancer. Urology 61:774-780

23. Jemal A, Tiwari RC, Murray T, Ghafoor A, Samuels A, Ward E, Feuer EJ, Thun MJ; American Cancer Society (2004) Cancer statistics, 2004. CA Cancer J Clin 54:8-29

24. Jemal A, Murray T, Ward E, Samuels A, Tiwari RC, Ghafoor A, Feuer EJ, Thun MJ (2005) Cancer statistics, 2005. CA Cancer J Clin 55:10-30

25. Jhaveri FM, Zippe CD, Klein EA, Kupelian PA (1999) Biochemical failure does not predict overall survival after radical prostatectomy for localized prostate cancer: 10-year results. Urology 54:884-890

26. Kantoff PW, Halabi S, Conaway M, Picus J, Kirshner J, Hars V, Trump D, Winer EP, Vogelzang NJ (1999) Hydrocortisone with or without mitoxantrone in men with hormone-refractory prostate cancer: results of the Cancer and Leukemia Group B 9182 Study. J Clin Oncol 17:2506-2513

27. Kattan MW, Eastham JA, Stapleton AM, Wheeler TM, Scardino PT (1998) A preoperative nomogram for disease recurrence following radical prostatectomy for prostate cancer. J Natl Cancer Inst 90:766-771

28. Kattan MW, Wheeler TM, Scardino PT (1999) Postoperative nomogram for disease recurrence after radical prostatectomy for prostate cancer. J Clin Oncol 17:1499-1507

29. Kattan MW, Zelefsky MJ, Kupelian PA, Cho D, Scardino PT, Fuks Z, Leibel SA (2003) Pretreatment nomogram that predicts 5 -year probability of metastasis following three-dimensional conformal radiation therapy for localized prostate cancer. J Clin Oncol 21:4568-4571

30. Konety BR, Eastham JA, Reuter VE, Scardino PT, Donat SM, Dalbagni G, Russo P, Herr HW, Schwartz L, Kantoff PW, Scher H, Kelly WK (2004) Feasibility of radical prostatectomy after neoadjuvant chemohormonal therapy for patients with high risk or locally advanced prostate cancer: results of a phase I/II study. J Urol 171:709-713

31. Kupelian P, Katcher J, Levin H, Zippe C, Suh J, Macklis R, Klein E (1997) External beam radiotherapy versus radical prostatectomy for clinical stage T1-2 prostate cancer: therapeutic implications of stratification by pretreatment PSA levels and biopsy Gleason scores. Cancer J Sci Am 3:78-87
32. Messing EM, Manola J, Sarosdy M, Wilding G, Crawford ED, Trump D (1999) Immediate hormonal therapy compared with observation after radical prostatectomy and pelvic lymphadenectomy in men with node-positive prostate cancer. N Engl J Med 341:1781-1788

33. Oh WK, George DJ, Kaufman DS, Moss K, Smith MR, Richie JP, Kantoff PW (2001) Neoadjuvant docetaxel followed by radical prostatectomy in patients with high-risk localized prostate cancer: a preliminary report. Semin Oncol 28:40-44

34. Partin AW, Yoo J, Carter HB, Pearson JD, Chan DW, Epstein JI, Walsh PC (1993) The use of prostate specific antigen, clinical stage and Gleason score to predict pathological stage in men with localized prostate cancer. J Urol 150:110-114

35. Partin AW, Mangold LA, Lamm DM, Walsh PC, Epstein JI, Pearson JD (2001) Contemporary update of prostate cancer staging nomograms (Partin tables) for the new millennium. Urology 58:843-848

36. Petrylak DP, Tangen CM, Hussain MH, Lara PN Jr, Jones JA, Taplin ME, Burch PA, Berry D, Moinpour C, Kohli M, Benson MC, Small EJ, Raghavan D, Crawford ED (2004) Docetaxel and estramustine compared with mitoxantrone and prednisone for advanced refractory prostate cancer. N Engl J Med 351:1513-1520

37. Pettaway CA, Pisters LL, Troncoso P, Slaton J, Finn L, Kamoi K, Logothetis CJ (2000) Neoadjuvant chemotherapy and hormonal therapy followed by radical prostatectomy: feasibility and preliminary results. J Clin Oncol 18:1050-1057

38. Picus J, Schultz M (1996) Docetaxel (Taxotere) as monotherapy in the treatment of hormone-refractory prostate cancer: preliminary results. Semin Oncol 26:14-18

39. Pilepich MV, Al-Sarraf M, Rotman M, Ratkin G, Zinninger M, Oss D (1986) Adjuvant chemotherapy with adriamycin, cytoxan, and cis-platinum in high-grade carcinoma of the prostate treated with definitive radiotherapy (RTOG pilot $81-$ 12). Am J Clin Oncol 9:135-138

40. Pound CR, Partin AW, Eisenberger MA, Chan DW, Pearson JD, Walsh PC (1999) Natural history of progression after PSA elevation following radical prostatectomy. JAMA 281:15911597

41. Roberts SG, Blute ML, Bergstralh EJ, Slezak JM, Zincke H (2001) PSA doubling time as a predictor of clinical progression after biochemical failure following radical prostatectomy for prostate cancer. Mayo Clin Proc 76:576-581

42. Ryan CJ, Zelefsky MJ, Heller G, Regan K, Leibel SA, Scher HI, Kelly WK (2004) Five-year outcomes after neoadjuvant chemotherapy and conformal radiotherapy in patients with high-risk localized prostate cancer. Urology 64:90-94

43. Schmidt JD (1984) Cooperative clinical trials of the National Prostatic Cancer Project: Protocol 900. Prostate 5:387-399

44. Schmidt JD, Gibbons RP, Murphy GP, Bartolucci A (1996) Evaluation of adjuvant estramustine phosphate, cyclophosphamide, and observation only for node-positive patients following radical prostatectomy and definitive irradiation. Investigators of the National Prostate Cancer Project. Prostate 28:51-57

45. Schmidt JD, Gibbons RP, Murphy GP, Bartolucci A (1996) Adjuvant therapy for clinical localized prostate cancer treated with surgery or irradiation. Eur Urol 29:425-433

46. Schulman CC, Debruyne FM, Forster G, Selvaggi FP, Zlotta AR, Witjes WP (2000) Four-year follow-up results of a European prospective randomized study on neoadjuvant hormonal therapy prior to radical prostatectomy in T2-3N0M0 prostate cancer. European Study Group on Neoadjuvant Treatment of Prostate Cancer. Eur Urol 38:706-713

47. Shipley WU, Thames HD, Sandler HM, Hanks GE, Zietman AL, Perez CA, Kuban DA, Hancock SL, Smith CD (1999) Radiation therapy for clinically localized prostate cancer: a multi-institutional pooled analysis. JAMA 281:1598-1604

48. Smaletz O, Scher HI, Small EJ, Verbel DA, McMillan A, Regan K, Kelly WK, Kattan MW (2002) Nomogram for overall survival of patients with progressive metastatic prostate cancer after castration. J Clin Oncol 20:3972-3982 
49. Tannock IF (1985) Is there evidence that chemotherapy is of benefit to patients with carcinoma of the prostate? J Clin Oncol 3:1013-1021

50. Tannock IF, Osoba D, Stockler MR, Ernst DS, Neville AJ, Moore MJ, Armitage GR, Wilson JJ, Venner PM, Coppin CM, Murphy KC (1996) Chemotherapy with mitoxantrone plus prednisone or prednisone alone for symptomatic hormoneresistant prostate cancer: a Canadian randomized trial with palliative end points. J Clin Oncol 14:1756-1764

51. Tannock IF, de Wit R, Berry WR, Horti J, Pluzanska A, Chi KN, Oudard S, Theodore C, James ND, Turesson I, Rosenthal MA, Eisenberger MA; TAX 327 Investigators (2004) Docetaxel plus prednisone or mitoxantrone plus prednisone for advanced prostate cancer. N Engl J Med 351:1502-1512

52. Van Poppel H, De Ridder D, Elgamal AA, Van de Voorde W, Werbrouck P, Ackaert K, Oyen R, Pittomvils G, Baert L (1995)
Neoadjuvant hormonal therapy before radical prostatectomy decreases the number of positive surgical margins in stage T2 prostate cancer: interim results of a prospective randomized trial. The Belgian Uro-Oncological Study Group. J Urol 154:429-434

53. Wang J, Halford S, Rigg A, Roylance R, Lynch M, Waxman J (2000) Adjuvant mitozantrone chemotherapy in advanced prostate cancer. BJU Int 86:675-680

54. Zelefsky MJ, Kelly WK, Scher HI, Lee H, Smart T, Metz E, Schwartz L, Fuks Z, Leibel SA (2000) Results of a phase II study using estramustine phosphate and vinblastine in combination with high-dose three-dimensional conformal radiotherapy for patients with locally advanced prostate cancer. J Clin Oncol 18:1936-1941 